\title{
EXPERIENTIAL GROUPS IN GROUP COUNSELORS TRAINING: A VIEW THROUGH THE MULTIPLICITY OF CONTEXTS
}

\author{
Birutė Jakubkaitè, Rimantas A. Kočiūnas \\ Vilnius University, Lithuania \\ E-mail: birute.jakubkaite@fsf.vu.It, rimask@parkas.It
}

\begin{abstract}
Experiential groups are one of prevailing forms of group counsellor training, which is devoted to exploring group dynamics and other aspects of group work through direct personal experience. However, there is still too little research carried out in this topic and some lack of consistency appears in this field of research. The research reported here was aimed at analyzing group participants' perceptions of multiplicity of contexts, as a distinctive characteristic of such group, which appears due to different goals raised and variety of roles performed in the same group. A qualitative approach was employed in this study using semi-structured interviews with graduates from international group therapy program. 5 participants of the Group therapy training program at the Institute of Humanistic and Existential Psychology (Lithuania) were chosen for this study. Besides theoretical lectures, program participants went through three experiential groups that were guided by experienced group counselors and also gained sort-time group guiding experience. The work of all groups was observed by two program supervisors. Study participants were asked to share the experience about taking part in group counselors training program, mostly focusing on experiential groups and their discussions with supervisors. The data gathered during interviews then was subjected to thematic analysis. Based on the results, the main topics related to group multiplicity were revealed and discussed: intrapersonal context of participants; organizational context of the training program; interpersonal context and wholeness context. Intrapersonal context of participants was associated not only with their personal dynamics in experiential group process, but also with participant's personal traits, motivation, anticipatory expectations, attitude towards psychological help, the training program, other participants, experiential group counselors and supervisors. Talking about organizational context of the training program participants mentioned analysis writing that assisted in better understanding of experiential group processes and structuring own experience. Experiential groups and their supervision processes were perceived by participants as extended and complementing each other. Interpersonal context encompassed interactions with group participants, group counselors and supervisors. Wholeness context involved the perception of group dynamics in experiential group as well as in participating in the whole training program. Perception of this wholeness helped participants understand the multidimensionality of training and adapt to it. According to data of this study it can be noted that these various contexts are intertwined together, therefore it would be useful to focus separately on each of them in the future. This could assist in more detailed and clear understanding of their interactions.
\end{abstract}

Key words: counselor in training, experiential group, group counselors.

\section{Introduction}

Group is a distinctive form of psychological help different from individual psychological help, therefore good individual counseling or psychotherapeutic skills are not sufficient (Yalom \& 
Leszcz, 2005; Markus \& King, 2003). Group counseling is exceptional for different interrelations a whole); moreover, each of these levels has its own dynamics. According to Rowan (1993) and Barbender, Smolar and Fallon (2004), an ability to observe all of these levels and their dynamics is an important skill and the choice of intervention from one level to another, when and how it has to be done, is the essence of guiding the group (Pollack \& Slan, 1995). Therefore, the group counselor training requires the integration of two experiences - knowledge and practice. Essentials of group work assist the group counselors in organizing and giving meaning to these experiences. Taking this into account, many theorists and practitioners of group therapy (e.g., Yalom \& Leszcz, 2005; DeLucia, Bowman \& Bowman, 1989; Brabender et al, 2004) besides didactic educational methods emphasize the importance of observation of proficient group counselor work, a consistent and thorough professional supervision of group counselor's work, personal group experience and individual therapy in group counselor training. Similar requirements are also set in most organizations accrediting such specialists (e.g., The Council for Accreditation of Counseling and Related Education Programs Training Standards or The Association for Specialist in Group Work), as well as most of the master's and doctoral degree programs in psychology (by Schumaker, Ortiz \& Brenninkmeyer, 2011). These standards are also applied in Lithuania (e.g., group counselors are trained in Institute of Humanistic and Existential Psychology). This paper focuses on experiential training groups, which serve for integration of knowledge and practical experience.

\section{Background of the Problem}

Approach to experiential training groups. A successful training program has to enable a trainee to gain knowledge how a group process is related to the results of group work and how a group counselor can affect this process and its dynamics. Experiential groups have become the most prevalent training form of group counselors that is aimed to meet the requirements of group therapy training (Shumaker et al, 2011; Anderson \& Price, 2001; Merta, Wolfgang \& MacNeil, 1993). Group is a central training component where the lectures, case discussions and personal therapy takes place (Lennie, 2007). Despite the fact that experiential groups are incorporated into mandatory group counselor training programs more often (Shumaker et al, 2011; Markus \& King, 2003; Merta et al., 1993), there is no unanimous approach towards them. Some authors (e.g., Anderson \& Price, 2001; Yalom \& Leszcz, 2005; Geller, Norcross \& Orlinsky, 2005) reveal the benefits of these groups stating that this kind of personal involvement in group helps in better understanding of experiences of ordinary group members and giving meaning to gained theoretical knowledge on a personal and emotional level. As Yalom and Leszcz (2005) indicate, most of the students learning group counseling evaluated their group as the most beneficial experience in the whole training program. Geller et al. (2005) present similar data. They refer to an international survey of group counselors which states that $85 \%$ of all those who participated in experiential groups answered that they had at least one personally beneficial experience, and more that $75 \%$ stated this experience as having a positive influence on personal experience as well as professionalism. Anderson and Price (2001) indicate that despite certain negative evaluations of this experience, trainees perceive it as valuable and highlight its professional and personal benefits. According to Kaslow (1984), experiential training groups provide the future group counselor a multidimensional reflection of self experience in group that is obtained thanks to other group members. Other authors note the difficulties that arise for trainees in these groups: their complex negative experience and an adverse influence to study results. Anderson and Price (2001) and Merta et al. (1993) beside positive approach to the experience gained in these groups also indicates some difficulties arising in such training groups: competition with colleagues, a desire to boast, defensiveness, fear of condemnation, attempts to assist the proficient group counselor and thus avoid a sincere personal involvement. Lennie (2007) invites to deepen the understanding of ongoing processes in these groups and notes that an optimistic view towards experiential groups in counselors training can simply arise from their prevalence in the training programs and the lack of empirical studies. She writes that the widespread use of these groups and strong feelings arising in them are the phenomena that require systematic empirical studies, and wonders how many authors indicate the lack of these studies. In 1980 Stockton noted 
that despite the impressive increase in the literature about group work, the literature about group counsellor training is not abundant and often refers to statements without any scientific basis and overly general, abstract ideas. This, according to Stockton, Morran and Krieger (2004), also applies currently. And the limited empirical basis is still very controversial (Lennie, 2007).

Thus, not enough studies about the topic of experiential groups in counselors training are carried out and they lack consistency in order to refer to a comprehensive and accurate scientific basis of these groups. It is also too little known about personal experiences and psychological changes in experiential training group participants. Little scientific data is available on the proportion of positive and negative experiences in group participants and their role in further professional and personal functioning. There is a lack of systematic and comprehensive studies that could reveal and clarify the influence of these groups on professional and personal maturity of group counselors.

Multidimensionality of experiential group in group counselors training. The most popular experiential group model in counselors training is a group consisting of other trainees (Yalom \& Leszcz, 2005). Though usually there are attempts to avoid difficulties arising because of different roles in the group (Goodrich, 2008; Davenport, 2004; Merta \& Sisson, 1991) this is not always the case (Yalom \& Leszcz, 2005), therefore a multiple structure is distinctive characteristic of experiential groups in counselors training. On one hand, the experiential training group is a formally formed group that has clearly set goals - training of group counselors. On the other hand, it is the group that sets not only professional, but also personal or psychotherapeutic goals that create a background for group processes. It is also a group of colleagues whose personal traits and experiences influence the interactions in group. Thus, trainees are involved in many roles (such as a group leader, group participant, student, supervised and a colleague) and face difficulties in learning and performing them simultaneously (Olk \& Friedlander, 1992).

However, the more accurate and comprehensive description and substantiation of interaction features need consistent scientific descriptions and research that could help to evaluate the influence of different roles employed in the same group on training of group counseling and personal experience, and also could further reveal and evaluate the possibilities and limits of their compatibility more accurately.

The goal of this study is to analyze how experiential training group participants experience the multidimensionality in group. In order to accomplish this goal, a qualitative study strategy was employed, since it allows a disclosure and structural description of this kind of experience.

\section{The Researcher's Role}

In carrying out the qualitative studies the authors' role in gathering and analyzing the results is essential. The authors of this study are familiar with tradition and practice of qualitative studies and have the experience of psychological group counseling. Thus, inevitably while planning of this study, question choice and the primary assumptions are formulated on the basis of author beliefs: (a) that a group experience is valuable; (b) taking part in experiential training groups helps mastering theoretical knowledge and gaining important group counseling skills; (c) taking part in the experiential training groups can be most helpful in experiencing group dynamics and relationship diversity; (d) taking part in these groups is an intense personal experience; (e) participants of experiential training groups face multifaceted relations. Thus, most of attention while gathering and analyzing data was focused on the reflection of these beliefs and their possible influence.

\section{Methodology of Research}

\section{General Background of Research}

The study was organized and carried out according to the principals and requirements of thematic analysis (Braun \& Clarke, 2006). One of the advantages of this method is its flexibility that is associated with the ability to satisfy various theoretical approaches. Thematic analysis assists in identifying, analyzing and bringing out the themes emerging in the data. Also the possibility of 
interpretation of obtained data is available (Boyatzis, 1998). Considering the aim of this study, the inductive thematic analysis was chosen, i.e., themes are closely related to the obtained data. According to these principles crystallized out themes are not put into theoretical framework in advance, but emerge directly from the available data.

\section{Participants}

Participants of Group therapy training program at the Institute of Humanistic and Existential Psychology (Lithuania, Vilnius-Bir tonas) were chosen for this study. This training program goes through three stages.

During the first stage, program participants besides theoretical lectures go through three experiential groups that are guided by experienced group counselors and psychotherapists. Group work is being observed by two program supervisors. These experiential groups continue for three days. The work is intense: there are four 1.5 hour sessions during the day and afterwards there is a 2 hour group work and dynamic discussion. During the discussion group participants, group counselors and supervisors present their own views on the processes going on in the group.

During the second training stage, program participants gain short-time group guiding experience. They are participants as well as group counselors in these groups (every program participant guides the group for one day). Their work is being observed by supervisors. After four group work sessions (i.e., after one group work day) the overall (trainees and supervisor) group work discussion and supervision is held.

The third training stage is intended to organizing and guiding a psychotherapeutic group independently. This stage of the program is not included into this study.

5 people participated in this study -1 man and 4 women whose age was between 32 and 58 years (mean age 49 years). 4 participants have a background in psychology and 1 in pedagogy. Only one program participant has never had any group guiding experience. All the participants have participated previously (not within the framework of the program) in various experiential groups. Since the program is international, 2 participants have come from Russia, 2 from Latvia and 1 from Lithuania. All participants of the same training group who completed the first two stages of the program and fulfilled all the training requirements were chosen for the study.

\section{Data Collection}

Data of this study was gathered by structured interview. Study participants were asked to share the experience about taking part in the above mentioned two stages of training, mostly focusing on experiential groups and their discussions. Questions for study participants were formulated as follows: (a) share your experiences about participation in this program; (b) share your experiences about experiential groups when you were a participant; share your experiences about experiential groups when you were a participant as well as a group counselor; (c) share your experiences about experiential group discussions and supervisions when you were a participant and a group counselor. Also clarifying questions that arose from participant narratives were asked during the interview and were intended to reveal the experience and its perception. The interview took from 35 minutes to 1 hour and 5 minutes (mean duration - 55 minutes) and was tape-recorded. The participants who came from Russia and Latvia were interviewed in Russian. The main language of the study program was also Russian. The interview was held in the premises of the Institute, in a cozy, isolated room.

\section{Ethical Consideration}

In order to meet the ethical requirements, before the interview study participants filled an informed consent form. Participation in the study was voluntary. Study participants knew that their refusal to take part in the study will not have any influence on their further participation in the training program and their evaluation, and program lecturers and supervisors will not have any direct access to the interview. Study participants were informed about the fact that interviews will be recorded and they became familiar with the form and length of interview storage. Participant 
actual names were changed as well as details that could be helpful in identifying a certain excerption author were eliminated. Also, participants could receive all the information necessary for their decision to take part in the study or they could refuse to take part in the study at any point.

\section{Data Analysis}

Interview data was analyzed according to Braun and Clarke's (2006) recommendations and included the following stages: (a) interview transcription and multiple readings noting thoughts and remarks; (b) primary coding when the transcribed data was systematized into codes; (c) theme search when the coded data was grouped into primary themes; (d) theme review in search of relationships with systematized data and codes; (e) theme establishment and naming; (f) selection of interview quotes that best describe the themes.

\section{Limitation}

As every scientific research this study has its limitations. Qualitative study strategy does not allow making generalizations - all study results are presented only in the context of a described group. The study is aimed not at wide generalization of results, but at raising further questions about the research of experiential groups in group counselors training. Moreover, it is important to note that only participants who fulfilled the training program were chosen for this study and the ones who discontinued the program were not included. This narrows down the results and their interpretation. Study results are limited to the notion that study participants represent one approach to group therapy. The inclusion of different training programs in such studies could widen the perception of experiential training group experience.

\section{Results of Research}

Analyzing the available data four main groups of themes emerged that concerned these contexts: intrapersonal context of participants; organizational context of the training program; interpersonal context; wholeness context.

Intrapersonal context of participants involved the following themes: (a) previous training and psychotherapeutic experience; (b) personal traits of a participant, current difficulties and personal changes; (c) individual motivation to learn.

Organizational context of the training program included the following themes: (a) training structure; (b) writing and reading analyses.

Interpersonal context included the following themes: (a) interaction with other participants; (b) interaction with experienced group counselors; (c) interaction with supervisors.

Wholeness context involved: (a) supervision as a distinctive form of experiential group followup; (b) wholeness is a group.

Intrapersonal context of participants: (a) previous training and psychotherapeutic experience. One of the components of intrapersonal context of participants is their own previous training and psychotherapeutic experience. Referring to it, group participants outlined the anticipatory expectations towards training program, experiential groups, and behavior of other participants, group counselors and supervisors. When referring to anticipatory expectations group participants also chose their own behavior that is either helping them to adapt to program requirements or interferes with it.

/.../I learning in group seemed to me like skill training. Well, such training, well ... I have participated in this kind of trainings before. There is a certain program when a counselor has certain exercises you can take part in or not. Or even taking part you cannot get involved much personally. Say, I expected something like this. I am going to learn psychotherapeutic tools, techniques, and methods that the group counselor uses. And I never expected I will have to "take my shirt off". And I behaved like I would in this kind of skill training group when I do not want to disclose myself.

1 All citation in original languages (Lithuanian and Russian) are available by e-mail: birute.jakubkaite@fsf.vu.lt 
The previous psychotherapeutic experience is usually associated with their choice to learn Volume 5, 2013 how to guide psychotherapeutic groups and reflects a whole belief in the value of psychological as well as group help.

/../ I understood and was certain that psychotherapeutic work, no matter if its individual or group, nonetheless give these kinds of significant and polysemantic effects. There were changes happening in my life and somehow I was completely persuaded that it is necessary. And when I came here to study, I already had experience, a great one.

Intrapersonal context of participant: (b) personal traits of a participant, current difficulties and personal changes. Other component of intrapersonal context is personal traits of participants and their current difficulties which directly arise while participating in experiential groups and are also associated with their feelings and behavior during experiential groups and discussions.

/... / Coming to the group itself has always made me anxious. Considerable amount of anxiety. Overall, anxiety is my trait and it is one of the biggest problems form me in this period of my life.

Study participants notice an increasing personal discomfort in the initial part of groups and discussions. It is a specific component of intrapersonal context that is mentioned by participants as a kind of interference when shifting from group participant to other (trainees or group counselor) positions.

/... / This training, it is somehow different that it is, at least in my opinion, very deep and it exposes problems.

Speaking about their own experience participants often mention significant personal changes reflected in their participation in the program and their personal as well as professional life, and their further participation in this training program. One of these changes is a greater consistency in group guiding skills and acquired knowledge with their personality.

/.../ and group counselor learns how to be a counselor "inside". This is very beneficial for me. It is important, well, I was shocked when I discovered for the first time that group counselors I.../ you are taught how to be a professional inside and relate it to yourself, your mind.

Intrapersonal context of participant: (c) individual motivation to learn. Despite the fact that participating in experiential groups experiential motivation itself is important as oriented more to personal disclosure, understanding of self and others, in participant interviews the fact emerges that clearly perceived training motivation is what helps them to continue the program when facing a complicated experience. Namely this motivation encourages them to better understand the experience that is intense and raising stress.

/... / I wanted to learn and with me, I had a very clear goal to acquire skills that I did not have. For me, I understood that I will not have time for this in my life anymore. It is the last chance for me. Here I understood that this, well, this is what I will never have this kind of chance anymore. And if I want to change something in my life, whether I can change it or not, I still don't know, I do not know. And what I can do about this - is to stay in this program. I was highly motivated.

Organizational context of the training program: (a) training structure. Talking about their experiences group participants note that formal training structure adds to the intensity of experiences. Intensive program holds tension and altering work nature - the experiential group and the discussion followed by it - intensifies participant experience, helps in acknowledging them, and encompasses more nuances of group work. However, experiencing intense feelings training participants shift with greater difficulty from the role of a group participant to group discussant and this results in additional, mostly challenging, experiences.

/.../ and it is also due to a few people. Fairly long and long lasting work. Analyses that we carried out afterwards, that we wrote afterwards, that is also follow-up. Supervisions-follow-up. Well, so many edges and grounds. /... / Difficulties were caused by the fact that there had always been recognition of one more follow-up, after the group is done with its work, and the completion of supervisors. The analysis, and follow-up, and other focuses of the view to situation, there. And when, well, when the time passed, viewing from the distance, it seemed that everything is settling and concentrating, and this analysis writing for me was one of the ways to return to one more group. Like the same thing once again. And the experience of this great, greater distance and maybe from such a distant viewpoint. Although I cannot say that it was the same thing with all of 
the groups. Well, it was filled and colored emotionally with such a great, great tension.

Organizational context of the training program: (b) writing and reading analyses. One of the most mentioned training program requirements mentioned by participants is analysis writing. These experiences initially cause resistance, but help in structuring and professionally defining their experiences. Analysis writing requires conscious effort and teaches a deeper reflection and flexibility in combining participant and trainee roles, the more because group participants write down notes on their own initiative in the initial training process. These informal notes help them handle group processes and take part in discussion more efficiently. Also writing lessens the intensity of experiences outlived in group and allows reflecting on them later.

/.../ we had this little scheme how to do the analysis. This has also helped to give structure, it gave a serious thought. Here is an important connection, right? You sit there yourself and then you start to give meaning to this structure.

Interpersonal context: (a) interaction with other participants. First when talking about their experiences training participants mention interpersonal relations that are affected by their likes, attitudes towards professional background, knowledge, and experience of others. These components color personal interactions of participants.

/.../ personal likes are more important for me and this kind of individual people perception. /.../ but it was very important for me what I feel towards that person, that kind of feelings he triggers in me.

Obviously, training participants perceive collegiality and support for each other differently.

/.../ I expected that the group will support me, simply because basically everyone will end up in this kind of position, and when it didn't happen, I basically stamped in one place. I made some kind of mistakes.

Common experiences modified the interactions and most of participants of this training group began to conceptualize others as "deep colleagues" with whom they can talk about everything and firstly about themselves in the relationships.

/... / Now we can talk about what we want. And about ourselves. I have in mind, not about something, about myself. And namely about myself in the interpersonal relationships. It is not that I am acting somehow somewhere, but right here and now we can talk to each other. There. That we are colleagues. Deep colleagues, profound colleagues. We understand when we are talking. We understand, we become aware, we are involved, we can listen to each other and hear, what a person is saying.

However, there were participants who perceived others as competing, unsupportive, oriented to evaluations, insufficiently competent to be equal training participants and written analyses or feedback of others would not be valuable.

/... / I lacked a deeper analysis and I lacked such, well, such commonness, analysis commonness was missing, because it seemed to me that there was an orientation towards evaluations and willingness to conform the standards. And I wanted a professional refining, maybe. Such completeness. I don't need any evaluation now.

These relationships reflected in participant interactions in experiential groups. Interactions that take place in experiential groups especially when significant conflicts and dislikes were present disturbed the receiving of feedback and maintaining the role of group counselor. When intense relationships are present it is difficult to react to others from the group counselor position and easy to return to the interactions between group participants.

/... / It is yet related to unsolved problems in the group. Because I already entered the role of group counselor with some unresolved problems that were in the group and stayed there. They stayed unresolved. And with all this baggage I guided the group, entered the role, well function of the counselor. And when two of the participants clearly expressed aggression towards me, this aggression was strong enough and I did not withstand - I retreated to feelings. I drowned in my own feelings and I precisely realized that moment, but I was struck with intense emotionality with what happened there. Well, roughly, I simply fell out.

Interpersonal context: (b) relation to experienced group counselors. Other important component of interpersonal context is interaction with experienced group counselors who were mentioned as "training models" and who encourage group processes. An attitude towards the experienced 
group counselor and his work in group was commonly based on personal experience rather than professional analysis.

/.../ Well, the person who, well, the group counselor, the professional - he comes and leads the group. Well, actually a master-you can learn and see. There. Different styles, different approaches. Different methods.

/... / The variety of group counsellor styles and work, they also, well, like not that they provided the group with different direction, but they also provided with different possibilities to get close to your own problems, but differently. And encountering these problems, difficulties. And this is a very complex process.

Interpersonal context: (c) interaction with supervisors. It is one of the most mentioned components of interpersonal context. Training participants pay great attention to supervisors. Some of them mention that their presence is felt while working in experiential group. Initially supervisors are perceived as absolute authorities and sometimes an important portion of group counselor functions are attributed to them.

/.../ and the same happened to supervisors as well as group counselors, lecturers and my fellow trainees. They also became more casual, and I also began to notice many of their human traits.

/.../ first I perceived the work of supervisors as, maybe, well ... well, such seeing from the distance, if I can say that. And it always seemed to me that some personal supervisor existence still can be felt.

Wholeness context: (a) supervision as a distinctive form of experiential group follow-up. In narratives of study participants an association between experiential groups and their discussions is observed. Participants tend to see discussions as distinctive group process follow-up that encourages and corrects group processes.

/... / I perceived it as a follow-up, but in a new form. And there was no, well, that a clear set of boundaries. Nor in the group, or supervision, or group life. For me it is a plunge to one common process that is happening but in different blocks. It is like days of the week-Monday, Tuesday, Wednesday. It is the same. I do not exclude them and I do not exclude myself from this, I always was in the common process.

Participants notice that discussion deepens group processes and as the group processes deepen, the professional value of discussions increases.

/.../And after that everything become more serious, deep and professional, and the group processes started to become more serious and deep, and everything worked together. In a parallel.

Wholeness context: (b) wholeness is a group. When sharing their experiences group participants mention the discovery of perception of group dynamics that they associate with personal participation in experiential group as well as group work discussions. Perception of group dynamics encompasses not only the perception of a specific group process, but the perception of what is happening during training as a whole, in all contexts. This perception is also transferred to understanding of everyday interpersonal relations.

/... / And when I sat here in the firsts groups, I was concentrated, for example, on personal problems /... / But, ... when I kept learning and sat in groups, I suddenly noticed the group dynamics. This was a shock for me, right? That something is happening besides my problems and personal problems of other people. And relationships between us, like always there is something between us /... / And here to me it happened ... that deep perception, I understood that: what am I doing? And who is doing that here, right? Then they, we say it, what are we doing, and here I caught it, right? This group process, this group dynamics. That people are saying one thing and we can discuss personal problems, but there will be something always happening and it is an important process that I have not personally seen before.

\section{Discussion}

Experiential group in group counseling training does not exist by itself. As the analysis of experiences of this study participants shows, some intertwined contexts exist - intrapersonal context of participants, organizational context, interpersonal context and wholeness context. Experiential group and taking part in it is associated with all of these contexts. This interdependence of con- 
texts can be the source of great intensity of feelings and constantly mentioned tension. Obviously, group counselor in training is involved in many roles at the same time and as Olk and Friedlander (1992) note, he encounters difficulties performing them in the same group.

Intrapersonal context of participants described in this paper is associated not only with their personal dynamics in experiential group process, but also with participant motivation, anticipatory expectations, attitude towards psychological help, the training program, other participants, experiential group counselors and supervisors. Personal traits and current difficulties of participants are reflected not only in the experiential group itself, but also in other contexts. Intensifying personal problems and stumbling on them not only causes intense feelings and tension, but also requires more participant efforts to take part in the training process, e.g., the supervision of experiential group. However, gaining more knowledge and understanding of group processes, participants become aware of their personal difficulties and anticipate forms of their control or solutions. This corresponds to Yalom and Leszcz's (2005) propositions that experiential training group provides an opportunity for future group counselors to experience what it means to be a group participant and link their knowledge with personal experience.

Group participants' feelings and experiences reflect how the training program is organized and also the participation in experiential groups. In this paper participants often mention auxiliary forms such as analysis writing and multiple readings that assist in better understanding of experiential group processes and structuring own experience.

Conducting further research of experiential groups it is also important to focus on the influence of organizational context in training on participant experience, and how the training program is organized. Currently there is more focus on the prevalence of groups and description of their structure (Markus \& King, 2003; Merta et al., 1993; Shumaker et al., 2011). The more so experiential groups and their supervision processes were perceived by this study's participants as extended and complementing each other and this interaction is little researched and is not clear.

Interpersonal context, encompassing interactions with group participants, group counselors and supervisors, is mentioned by participants when talking about their own vulnerability, fear of authority and evaluation, and support as well as understanding each other. Yalom and Leszcz (2005) take notice that professionally guided experiential groups can improve interrelations between training participants. The experience in this group would confirm these authors' opinion, because participants talk about being "deep colleagues", a sense of understanding and deep belonging. However, a sense of belonging can appear not only caused by positive experience. Painful experiences can also be unifying. These experiences of group participants confirm negative experience and learning difficulties, as described by Anderson and Price (2001) and Merta et al. (1993).

Wholeness context involves the perception of group dynamics in experiential group as well as in participating in the whole training program. Perception of this wholeness helps participants to better understand the multidimensionality of training. Like so, the perception of multidimensionality can assist in adapting more successfully to complex goals and requirements set for group counselors in training.

According to data of this study it can be noted that these various contexts are intertwined together, therefore it would be useful to focus separately on each of them in the future. This could assist in more detailed and clear understanding of their interactions.

\section{Conclusions and Implication}

The goal of this study was to analyze how participants of experiential groups in group counselors training perceive the multidimensionality of this group and provide a structured description. According to the data participants of group counseling training inevitably experience the existence of separate contexts in experiential groups. Firstly, every participant refers to prior experiences, expectations and attitudes that inevitably form the relations in the group. Personal traits and current difficulties are reflected not only in the processes of experiential group itself or interpersonal relations in the group, but also are apparent during the supervisions. The structured context of formal training program, analysis writing and reading is also noted in the experience of group participants as related to group processes and their understanding. Interpersonal relations with 
group participants, group counselors and supervisors create one more distinctive context that en-

compasses not only the experiential group, but also the interactions that exist in the whole training program. Program supervisors are important to group participants. The participants of this group perceived them as significant in their training and experiential processes, and the supervisions often were perceived as distinctive follow-up of group work. The perception of group dynamics encompasses not only the perception of processes of a specific group, but also the perception of what is happening during entire training, in all the contexts. This perception assists in understanding the existent multidimensionality and adapt to it.

\section{References}

Anderson, R. D., Price, G. E. (2001). Experiential Groups in Counselor Education: Student Attitudes and Instructor Participation. Counselor Education \& Supervision, 41, 111-119.

Brabender, V., Smolar, A. I., Fallon, A. E. (2004). Essentials of Group Therapy. Hoboken, NJ: John Wiley \& Sons.

Braun, V., Clarke, V. (2006). Using Thematic Analysis in Psychology. Qualitative Research in Psychology, 3, 77-101.

Boyatzis, R. E. (1998). Transforming Qualitative Information: Thematic Analysis and Code Development. Thousand Oaks, CA: Sage Publications.

Corey, M. S., Corey, G., Corey, C. (2010). Groups - Process and Practice (8th Ed.). Belmont, CA: Brooks/ Cole, Cengage Learning.

Davenport, D. S. (2004). Ethical Issues in the Teaching of Group Counseling Leadership training. The Journal for the Specialist in Group Work, 29 (1), 43-49.

DeLucia, J. L., Bowman, V. E., \& Bowman, R. L. (1989). The Use of Parallel Process in Supervision of Group Counseling to Facilitate Counselor and Client Growth. The Journal for Specialist in Group Work, 14, 232-238.

Friedlander, M. L., Keller, K. E., Peca-Baker, T. A., Olk, M. E. (1986). Effects of Role Conflict on Counselor Trainees' Self-Statements, Anxiety Level, and Performance. Journal of Counseling Psychology, 33 (1), 73-77.

Geller, J. D., Norcross, J. C., Orlinsky, D. E. (2005) The Psychotherapists own Psychotherapy - Patient and Clinical Perspectives. New York: Oxford university press.

Goodrich, K. M. (2008). Dual Relationships in Group Training. The Journal for Specialist in Group Work, $33,221-235$.

Kaslow, F. W. (1984). Psychotherapy with psychotherapists. New York: The Haworth Press.

Lennie, C. (2007). The Role of Personal Development Groups in Counsellor Training: Understanding Factors Contributing to Self-awareness in the Personal Development Group. British Journal of Guidance and Counseling, 35 (1), 115-129.

Markus, H. E., King, D. A. (2003). A Survey of Group Psychotherapy Training During Predoctoral Psychology Internship. Professional Psychology: Research and Practice, 34 (2), 203-209.

Merta, R. J., Sisson, J. A. (1991). The Experiential Group: An Ethical and Professional Dilemma. The Journal for Specialist in Group Work, 16, 236-245.

Merta, R. J., Wolfgang, L., MacNeil, K. (1993). Five Models for Using the Experiential Group in the Preparation of Group Counselors. The Journal for Specialist in Group Work, 18, 200-207.

Olk, M. E., Friedlander, M. L. (1992) Trainees' Experiences of Role Conflict and Role Ambiguity in Supervisory Relationships. Journal of Counseling Psychology, 39, 389-397.

Pollack, H. B., Slan, J. B. (1995). Reflections and Suggestions on Leadership of Psychotherapy Groups. International Journal of Group Psychotherapy, 45 (4), 507-519.

Rowan, J. (1993). The Transpersonal: Psychotherapy and Counseling. London: Routledge.

Shumaker, D., Ortiz, C., Brenninkmeyer, L. (2011). Revisiting Experiential Group Training in Counselor Education: A Survey of Master's-Level Programs. The Journal for Specialist in Group Work, 36 (2), $111-128$ 
ISSN 2029-8587

PROBLEMS

OF PSYCHOLOGY

IN THE $21^{\text {st }}$ CENTURY

Volume 5, 2013

22

Stockton, R. (1980). The Education of Group Leaders: A Review of the Literature with Suggestions for the Future. The Journal for Specialist in Group Work, 5, 55-62.

Stockton, R., Morran, D. K., Krieger, K. M. (2004). On Overview of Current Research and Best Practices for Training. In DeLucia-Waack, J.L., Gerrity, D.A., Kalodner C.R., Riva, M.T. (Eds). Handbook of group counseling and group psychotherapy (pp.65-75). Thousand Oaks, CA: Sage Publications.

Yalom, I.D., \& Leszcz, M. (2005). The theory and practice of group psychotherapy (5th Ed.). New York: Basic Books.

Advised by Paulius Skruibis, Vilnius University, Vilnius, Lithuania.

Received: January 28, 2013

Accepted: March 18, 2013

Birutė Jakubkaitė Master Degree in Clinical Psychology, Postgraduate Student (Doctoral Studies) Vilnius University, Department of Clinical and Organizational Psychology, Universiteto Street 9/1, Vilnius Lithuania.

E-mail: birute.jakubkaite@fsf.vu. It 